\title{
INTRAVESICAL INSTILLATION OF GENTAMICIN SULFATE: IN VITRO, RAT, CANINE, AND HUMAN STUDIES
}

\author{
J. WAN, M.D. \\ M. KOZMINSKI, M.D. \\ S. C. WANG, M.D. \\ G. J FAERBER, M.D
}

E. J. MCGUIRE, M.D.

D. A. BLOOM, M.D.

M. L. RITCHEY, M.D.

From the Section of Urology, University of Michigan, Ann Arbor, Michigan

\begin{abstract}
Objective. Intravesical instillation of gentamicin sulfate has been used empirically as prophylaxis and to treat bacilluria in spinal-cord-injured patients undergoing clean intermittent catheterization. To assess the risks of absorption and the effects of storage conditions on antimicrobial potency, a series of studies were conducted.

Methods. Four studies were carried out: (1) An infected fulgurated rat bladder model was created to determine the effects of inflammation and infection on absorption. (2) A canine model with bilateral vesicoureteral reflux and elevated bladder pressures ( $>40$ $\mathrm{cmH}_{2} \mathrm{O}$ ) assessed the effects of reflux and storage pressure. (3) The effects in patients with associated conditions including renal transplantation, myelomeningocele, vesicoureteral reflux, and bladder augmentation, were analyzed. (4) To determine the effects of storage conditions, solutions of gentamicin sulfate ( $480 \mathrm{mg}$ gentamicin sulfate in $1 \mathrm{~L} 0.9 \% \mathrm{NaCl}$ ) were made that controlled for $\mathrm{pH}$, storage temperature, and duration.

Results. (1) Increased absorption was found in 43 percent of rat serum samples. (2) None of the dogs demonstrated measurable absorption. (3) None of the patients likewise had measurable absorption. (4) All solutions were equally potent when tested against a panel of common urinary pathogens. Storage up to two months at room temperature without alkalinization had no effect on potency.

Conclusions. Instilled intravesical gentamicin sulfate has a low risk of absorption and is highly effective. Severe bladder inflammation can increase transvesical absorption. It has prolonged stability without special storage conditions and should be considered as a route of prophylaxis in patients who perform intermittent catheterization.
\end{abstract}

Direct intravesical instillation of antibiotics for bladder infections offers some advantages over oral therapy. The drug is brought directly to the site of action, and the impermeability of the bladder minimizes systemic effects. Bypassing the gastrointestinal tract avoids nausea, diarrhea, and colonic superinfection associated with some oral agents. There is concern, however, that absorption of intravesical antibiotics could be increased in an infected bladder with an inflamed epithelium. This is also of concern in patients with vesicoureteral reflux, prior enterocystoplasty, or renal transplantation.

Submitted: September 28, 1993, accepted (with revisions): December 3, 1993
The aminoglycoside gentamicin was selected for investigation as an intravesical agent. We had used it empirically for antimicrobial prophylaxis and for treatment of bacilluria in adult spinal-cord-injured patients undergoing clean intermittent catheterization (CIC). A series of experiments were then constructed using rat and canine models to investigate the absorption of intravesical gentamicin in the presence of an active urinary infection and vesicoureteral reflux. In vitro testing was done to determine the effects of $\mathrm{pH}$ and temperature as well as duration of shelf storage on antibiotic potency. Finally the absorption of intravesical gentamicin in patients was measured in a variety of clinical situations including bladder augmentation, vesicoureteral reflux, and renal transplantation. 


\section{MATERIAL AND METHODS}

RAT INFECTION MODEL

An infected fulgurated rat bladder model was created using a previously described technique. ${ }^{1}$ Seven adult rats (body weight, 125-250 g) were anesthetized with intraperitoneal pentobarbital (45 mg/kg). The lower abdomen was shaved and cleaned with povidone-iodine. A midline incision was made to expose the bladder. A 27-gauge hypodermic needle transmurally drained and collapsed the bladder. The dome of the bladder was opened with a scalpel. The posterior bladder wall epithelium was fulgurated with needle tip electrocautery. The cystotomy was closed with a single continuous 5-0 chromic suture. A clinical isolate of Escherichia coli from the hospital microbiology laboratory was the infecting agent. One cc of a transport media broth from a twenty-four-hour E. coli urine culture documented to have one million colonies per milliliter was injected into the bladder. The abdomen was closed with a single 2-0 chromic suture. After one week the rats were again anesthetized, prepped, and the incision was reopened to expose the bladder. Urine was aspirated from the bladder through a needle and was cultured. All specimens showed active infection ( $>1,000,000$ colonies $/ \mathrm{mL}$ ). One cc of a gentamicin sulfate (GS) solution ( $480 \mathrm{mg} \mathrm{GS} / 1 \mathrm{~L} 0.9 \% \mathrm{NaCl}$ ) was injected back down the needle into the intact bladder. Venous blood was drawn from the inferior vena cava thirty minutes after intravesical instillation and gentamicin levels were determined using a standard assay.

\section{CANINE MODEL}

A dog model was created to determine the effect of elevated bladder pressures and vesicoureteral reflux on absorption of intravesical gentamicin. Fluoroscopic cystograms were performed on six adult mongrel female dogs (weight, 23 to $30.5 \mathrm{~kg}$ ) under halothane anesthesia using $60 \%$ Hypaque meglumine. Two of the animals (\#5 and \#1) demonstrated natural bilateral vesicoureteral reflux during gravity filling with contrast media. The other four animals were prepped and underwent a low midline incision to expose the bladder. The bladder was opened and a generous ureteral meatotomy and partial division of the intravesical sheath were performed. The free edges were sewn back with fine absorbable suture. The bladder was closed with two layers of absorbable sutures. Repeat fluoroscopic cystograms showed bilateral vesicoureteral reflux in all six dogs at bladder pressures of 7 to $15 \mathrm{~cm} \mathrm{H} \mathrm{H}_{2} \mathrm{O}$. A GS solution $(240 \mathrm{mg}$ $\mathrm{GS} / 1 \mathrm{~L} 0.9 \% \mathrm{NaCl}$ ) was then infused the same day through a urethral catheter. The retention balloon had been filled with $5 \mathrm{cc}$ sterile $\mathrm{NaCl}$ and the catheter pulled down to occlude the vesical outlet. The GS solution was forcefully infused until a pressure of $40 \mathrm{~cm} \mathrm{H}_{2} \mathrm{O}$ was reached. Serum for gentamicin levels was taken at zero and thirty minutes after the maximum pressure had been reached. Serum creatinine levels were drawn at zero minutes and three days postinfusion.

\section{IN VITRO MODEL}

To determine the effect of storage conditions such as $\mathrm{pH}$, age, and temperature a set of GS solutions was prepared ( $480 \mathrm{mg} \mathrm{GS} / 1 \mathrm{~L} 0.9 \% \mathrm{NaCl}$ ). The bottles were divided into two groups. The first group was alkalinized to a $\mathrm{pH}$ of 8 with $100 \mathrm{mEq}$ $\mathrm{NaHCO}_{3}$. The second group was left unalkalinized with a $\mathrm{pH}$ of 5 . Within each group the bottles were again divided so that half were stored in a household food refrigerator $\left(2-7^{\circ} \mathrm{C}\right)$ while the others were kept at room temperature $\left(15-25^{\circ} \mathrm{C}\right)$. The bottles within each $\mathrm{pH}$ and temperature group were then separately aged two months, one month, and two weeks. A total of twelve bottles of GS solution representing the different $\mathrm{pH}$, temperature, and shelf age combinations were thus made. Comparisons of potency were made between the aged and two fresh solutions of gentamicin sulfate (with and without $\mathrm{NaHCO}_{3}$ ) using a modified disk susceptibility technique. ${ }^{2}$ Filter paper disks (6.35 mm diameter; Schleicher \& Schnell, Keene, NH) were loaded with $20 \mu \mathrm{L}$ aliquots pipetted from each bottle. Mueller Hinton agar plates (150 mm size) were seeded with samples of genitourinary pathogens gathered from positive urine cultures found by the hospital clinical microbiology laboratory. Isolates of E. coli, Pseudomonas aeruginosa, Enterobacter cloacae, Streptococcus fecalis, Proteus mirabilis, Klebsiella pneumoniae, and coagulase-positive Staphylococcus were resuspended to a concentration that yielded a $\mathrm{BaSO}_{4} \mathrm{McF}$ arland standard of 0.06 absorbance units as measured by a spectrophotometer (Bausch \& Lomb, Rochester, NY). These bacterial suspensions were then plated on the agar plates as a series of nonoverlapping concentric rings. The disks loaded with the GS solutions along with a commercially prepared control disk of GS $(10 \mu \mathrm{g} / 20 \mu \mathrm{L}$, yielding an effective disk concentration of $500 \mu \mathrm{g} / \mathrm{mL}$ or $500 \mathrm{mg} / \mathrm{L}$ ) were then placed on the plates with ample separation between each disk to prevent cross-disk interference. The plates were then inverted to prevent condensation on the agar surface and incubated at $35^{\circ} \mathrm{C}$ for eighteen hours. Three measurements of the diameters of the zones of inhibition were made 


\begin{tabular}{cc}
\hline $\begin{array}{c}\text { TABLE I. } \\
\text { in the fulgurated rat bladder model }\end{array}$ \\
\hline $\begin{array}{c}\text { Rat Number } \\
\text { Rentamicin Level in inferior } \\
\text { Vena Cava at }\end{array}$ 30 Minutes $(\mu \mathrm{g} / \mathrm{mL})$ \\
\hline 1 & 4.3 \\
2 & 2.4 \\
3 & $<1.0$ \\
4 & 2.7 \\
5 & $<1.0$ \\
6 & $<1.0$ \\
7 & $<1.0$ \\
\hline
\end{tabular}

using graduated calipers and the average was recorded. The results were then analyzed using a computer software package.

\section{HUMAN STUdiES}

Ten children who perform CIC for neurogenic bladders were placed on bladder instillation with GS (480 mg GS/1 L $0.9 \%$ NS). Four boys and six girls were aged from one to eighteen years. Their conditions represented a variety of diagnoses with the most common being myelomeningocele. All patients demonstrated bacteriuria on urinalysis. Three patients had vesicoureteral reflux and three had undergone augmentation enterocystoplasty. Two patients subsequently had renal transplantation while on GS irrigation. Each patient instilled 30 to $60 \mathrm{~mL}$ of GS solution twice a day at the conclusion of a regularly scheduled catheterization. The GS solution was left to dwell after instillation. All had serum gentamicin levels drawn thirty minutes after instillation and had creatinine levels monitored during therapy. Cultures were obtained at the start of therapy and after one week of treatment.

\section{RESULTS}

\section{RAT INFECTION MODEL.}

Four animals had no measurable serum levels of gentamicin (Table I). Absorption of gentamicin was noted in three of seven rats $(43 \%)$, but absorbed serum levels were all in the low-nontoxic range for the laboratory ( 4 to $12 \mu \mathrm{g} / \mathrm{mL}$ ).

\section{CANINE MODEL}

Serum levels of gentamicin were not detectable at time zero minutes or after thirty minutes of maximum intravesical pressure (Table II). Serum creatinine levels were not altered.

\section{IN VITRO MODEL}

The $\mathrm{S}$. fecalis plate showed small inhibition diameters $(\leq 12 \mathrm{~mm})$ consistent with drug resistance in all disks. ${ }^{3}$ This was an expected finding because $\mathrm{S}$. fecalis is known to be resistant to aminoglycosides. ${ }^{3,4}$ On all the other plates, all disks had inhibition diameters $(\geq 15 \mathrm{~mm}$ ) consistent with marked drug sensitivity. ${ }^{3}$ Repeated analyses of variance were performed and did not find any significant differences between the size of the zone diameters of the disks on each plate $(\mathrm{P}<0.01$, Table III). This implied that each solution on each plate was equally effective regardless of storage condition. The unalkalinized solutions were as potent as those treated with $\mathrm{NaHCO}_{3}$. Room temperature and aging up to two months had no effect on potency.

\section{HUMAN DATA}

None of the patients at thirty minutes after installation had detectable serum levels of gentamicin sulfate and serum creatinine levels remained unchanged (Table IV). None of the patients encountered any difficulty with the instillation. There were no adverse reactions. Urine cultures grew out $>100,000$ colonies $/ \mathrm{mL}$ of $\mathrm{E}$. coli in 3 patients prior to treatment. None of the children had development of fungal infections or bladder colonization with organisms resistant to gentamicin. All had negative urine cultures after one week of therapy.

\section{COMMENT}

Intravesical medications have a long history of use for superficial transitional cell carcinoma of the bladder. High concentrations of antineoplastic agents can be achieved with minimal absorption; hence, few systemic side effects occur. Intravesical

TABLE II. Serum gentamicin sulfate and creatinine levels in the dog reflux model

\begin{tabular}{cccccc}
\hline Dog Number & $\begin{array}{c}\text { Weight } \\
(\mathrm{kg})\end{array}$ & $\begin{array}{c}\text { Serum Gentamicin Level } \\
(\mu \mathrm{g} / \mathrm{mL}) \text { at Time } 0\end{array}$ & $\begin{array}{c}\text { Serum Gentamicin Level } \\
(\mu \mathrm{g} / \mathrm{mL}) \text { at } 30 \text { Minutes }\end{array}$ & $\begin{array}{c}\text { Serum Creatinine Level } \\
(\mu \mathrm{g} / \mathrm{mL}) \text { at Time } 0\end{array}$ & $\begin{array}{c}\text { Serum Creatinine Level } \\
(\mu \mathrm{g} / \mathrm{mL}) \text { at } 3 \mathrm{Days}\end{array}$ \\
\hline 1 & 28 & $<0.5$ & $<0.5$ & 1.2 & 1.2 \\
2 & 30 & $<0.5$ & $<0.5$ & 1.0 & 1.2 \\
3 & 23 & $<0.5$ & $<0.5$ & 1.3 & 1.0 \\
4 & 30.5 & $<0.5$ & $<0.5$ & 1.0 & 1.2 \\
5 & 27 & $<0.5$ & $<0.5$ & 1.0 & 1.0 \\
6 & 23.5 & $<0.5$ & $<0.5$ & 1.2 \\
\hline
\end{tabular}


TABLE III. Diameters of zone of inhibition $(\mathrm{mm})$ of different gentamicin sulfate solutions

\begin{tabular}{|c|c|c|c|c|c|c|c|}
\hline Solution & P. aeruginosa & S. fecalis & E. coli & E. cloacae & P. mirabilis & K. pneumoniae & $\begin{array}{l}\text { Coagulase-Positive } \\
\text { Staphylococcus }\end{array}$ \\
\hline Control & 16.5 & 11.4 & 21.8 & 21.8 & 21.3 & 22.1 & 25.8 \\
\hline Fresh B & 17.7 & 11.4 & 21.8 & 21.8 & 22.8 & 22.1 & 25.0 \\
\hline Fresh & 16.6 & 11.4 & 22.8 & 22.1 & 22.6 & 22.0 & 25.0 \\
\hline $2 \mathrm{moBF}$ & 15.6 & 12.4 & 22.0 & 21.8 & 21.4 & 21.7 & 24.9 \\
\hline 2 mo BR & 15.6 & 10.4 & 22.8 & 21.8 & 21.1 & 22.1 & 25.1 \\
\hline $2 \mathrm{moF}$ & 16.6 & 10.4 & 22.5 & 21.8 & 21.8 & 22.1 & 24.9 \\
\hline $2 \mathrm{moR}$ & 16.6 & 10.4 & 22.8 & 21.8 & 21.8 & 22.1 & 25.1 \\
\hline $1 \mathrm{moBF}$ & 17.6 & 10.6 & 22.8 & 22.8 & 21.8 & 22.5 & 25.1 \\
\hline $1 \mathrm{moBR}$ & 16.6 & 11.4 & 22.9 & 22.8 & 22.8 & 22.6 & 25.2 \\
\hline $1 \mathrm{moF}$ & 17.6 & 11.4 & 22.8 & 22.1 & 22.4 & 22.4 & 25.0 \\
\hline $1 \mathrm{moR}$ & 16.6 & 11.4 & 21.9 & 22.7 & 22.8 & 23.0 & 25.7 \\
\hline $2 w k B F$ & 16.5 & 10.4 & 22.8 & 22.8 & 22.1 & 22.1 & 25.1 \\
\hline $2 w k B R$ & 166 & 10.7 & 22.8 & 22.8 & 22.1 & 22.0 & 25.0 \\
\hline $2 w k F$ & 16.9 & 11.4 & 22.8 & 22.2 & 22.1 & 21.2 & 25.0 \\
\hline 2 wk R & 17.8 & 11.4 & 22.8 & 22.5 & 21.8 & 22.0 & 25.4 \\
\hline
\end{tabular}

\begin{tabular}{|c|c|c|}
\hline \multicolumn{3}{|c|}{ TABLE IV. } \\
\hline $\begin{array}{l}\text { Patient No. } \\
\text { Sex-Age (yrs) }\end{array}$ & $\begin{array}{l}\text { Serum Gentamicin } \\
\text { Level }(\mu \mathrm{g} / \mathrm{mL})\end{array}$ & Comments \\
\hline $1-M-6$ & $<0.5$ & Solitary kidney, VUR \\
\hline $2 \cdot F-2$ & $<0.5$ & MMC \\
\hline $3-M-11$ & $<0.5$ & Txp, augmented \\
\hline $4-F-3$ & $<0.5$ & MMC \\
\hline $5-M-14$ & $<0.5$ & Txp, augmented \\
\hline $6-M-7$ & $<0.5$ & MMC. VUR \\
\hline $7-F-2$ & $<0.5$ & MMC, VUR \\
\hline $8-F-18$ & $<0.5$ & MMC, augmented \\
\hline G.F-5 & $<0.5$ & $M M C$ \\
\hline $10-F-8$ & $<0.5$ & Crohn's disease \\
\hline
\end{tabular}

Key: $V U R=$ vesicoureteral reflux; $M M C=$ myelomeningocele; $T x p=$ renal transplantation; augmented = enterocystoplast $y$.

instillation of antibiotics is a similar form of brachytherapy that offers several distinct advantages over oral and parenteral antimicrobial therapy. Gastrointestinal upset or diarrhea associated with some oral preparations is avoided. The body's normal colonic flora is much less likely to be disturbed, thereby lessening the risk of pseudomembranous colitis or fungal superinfection. The principal disadvantages have been concerns about effectiveness, bladder epithelial irritation, toxic absorption, and the inconvenience of having to pass a catheter. These perceptions are reflected in many of the early studies of instilled antibiotics that focused on individuals who were irrigated through indwelling catheters as a prophylactic measure against perioperative cystitis. ${ }^{5-7}$ Ball et al..$^{5}$ studied the effects of chlorhexidine in men after transurethral surgery. Chamberlain and Needham ${ }^{6}$ investigated polymixin $\mathrm{B}$, bacitracin, and neo- mycin irrigations in women who underwent hysterectomy. Giannoni et al. ${ }^{7}$ evaluated 300 men who were irrigated with povidone-iodine after transurethral resection of the prostate. These studies and others found fewer episodes of symptomatic bacteriuria while patients were on irrigation, but also confirmed suspicions about possible limitations of the technique. ${ }^{5-10}$ Certain agents such as acetic acid irritated the bladder epithelium and caused ulcers. ${ }^{10}$ Others such as chlorhexidine were poorly effective against common iatrogenic pathogens such as Pseudomonas. ${ }^{11}$ The value of intravesical therapy compared to simple closed drainage or conventionally administered medications was questioned. ${ }^{12}$

The development and popularization of $\mathrm{ClC}$ as a reservoir-emptying technique renewed the interest in intravesical medications. ${ }^{13}$ Clean intermittent catheterization permitted new options in the management of neurogenic bladders, urologic cancers, and urinary tract reconstruction with bowel. Procedures and therapies that had poor clinical results prior to $\mathrm{CIC}$ because of inadequate urine drainage became practical. The utility of intravesical medications has likewise increased. Greenfield and Fera $^{14}$ showed that intravesical oxybutynin chloride can be used safely to manage hyperreflexic hypertonic bladders in children who could not otherwise tolerate oral medications at an effective dose. Massad and colleagues ${ }^{15}$ demonstrated a lack of significant systemic side effects despite detectable levels of absorbed intravesical oxybutynin higher than those found with orally administered drug. This observation was interpreted as suggesting that a hepatic metabolite generated by passage 
down the gastrointestinal tract may be responsible for the anticholinergic side effects. Other agents such as calcium channel blockers and tricyclic antidepressants, which are usually administered orally, also are effective intravesically. ${ }^{16}$ One of us (E.J.M.) has empirically used gentamicin sulfate for prophylaxis and treatment of bacterial cystitis for ten years in adult spinal-cord-injured patients on CIC who periodically experienced bacterial cystitis if not kept on oral antibiotics, and sometimes in spite of medication. The infections might be asymptomatic or present with cloudy malodorous urine or new-onset urinary leakage. None would be febrile, but all would have bacteriuria and all would have positive urine cultures. When GS instillation was begun, the urine would clear, cultures would become negative, and patients could stop taking oral agents. About 10 percent of all adult spinal-cord-injured patients evaluated by the authors utilize intravesical GS in this manner. ${ }^{17}$ To determine what factors may affect the safe and effective usage of intravesical GS, the studies presented here were conducted.

Gentamicin sulfate is an ideal intravesical antibiotic. It is a proven bactericide against most genitourinary pathogens (especially Pseudomonas species and other gram-negative organisms). First isolated as a derivative of Micromonospora purpurea in 1963, gentamicin has been widely used intravenously. ${ }^{18}$ Commercially synthesized as gentamicin sulfate, it is highly cationic and does not easily cross lipid membranes. When administered orally, it is poorly absorbed, although absorption has been noted when exposed to serosal surfaces, burns, and wounds during lavage or irrigation. ${ }^{18}$ Our findings in the rat model suggest that severe inflammation does increase absorption from the bladder. The canine and human data suggest that high intravesical pressure and vesicoureteral reflux without inflammation do not themselves predispose to increased absorption. However, although significant levels of absorbed gentamicin did not develop in any patient, further studies are needed to determine if monitoring of serum gentamicin levels is necessary in patients with bladder augmentation, renal failure, or those taking immunosuppressive drugs.

The effects of storage conditions are important to the usefulness of GS as an intravesical agent. For outpatients the convenience and economy of being able to prepare liter quantities of irrigation solution and store at room temperature is appealing. It is known that GS is more potent in an alkaline environment. Increased acidity can increase the minimal concentration needed to inhibit the growth of gram-negative bacilli eight to thirtytwo-fold. ${ }^{19}$ Prolonged exposure to higher temperatures $\left(>20^{\circ} \mathrm{C}\right)$, oxygen, and plastics has been identified as a factor that can lead to a loss of antimicrobial activity. ${ }^{20-22}$ The in vitro data demonstrate that GS can be safely stored without refrigeration or alkalinization and remains potent for up to two months.

Intravesical instillation of GS is safe and effective. For patients who perform CIC it should be considered as a route of prophylaxis against recurrent simple bacterial cystitis. It obviates the need for oral agents and their attendant risks. This evaluation of GS has established the criteria by which other potential intravesical antimicrobial agents can be judged: it has a low risk of absorption across a spectrum of clinical situations, it is highly effective against likely pathogens, and it demonstrates prolonged stability without special storage conditions.

\section{J. Wan, M.D. \\ Department of Pediatric U rology Children's Hospital of Buffalo 219 Bryani Street \\ Buffalo, New York 14222}

Acknowledgment. To Carl Pierson, Ph.D., of the University of Michigan Hospital Clinical Microbiology Laboratory for his assistance with the in vitro studies reviewed in this article.

\section{REFERENCES}

1. Bagley DH, Herlihy E, and McGuire EJ: Infections and antibiotic prophylaxis in the fulgurated rat bladder. Invest Urol 17: 277-283, 1980.

2. Bauer AW, Kirby WMM, Sherris JC, and Turck M: Antibiotic susceptibility testing by a standardized single disk method. Am J Clin Pathol 45: 493-496, 1966.

3. Acar JF, and Goldstein FW: Disk susceptibility test, in Lorian V (Ed): Antibiotics in Laboratory Medicine, ed 2, Baltimore, Williams \& Wilkins, 1986, pp 27-63.

4. Weinstein MJ, Luedemann GM, Oden EM, Wagman GH, Rosselet JP, Marquez JA, Coniglio CT, Charney W, Herzog HL, and Black J: Gentamicin, a new antibiotic complex from Micromonospora. J Med Chem 6: 463-464, 1963.

5. Ball AJ, Carr TW, Gillespie WA, Kelly M, Simpson RA, and Smith PJ: Bladder irrigation with chlorhexidine for the prevention of urinary infection after transurethral operations: a prospective controlled study. J Urol 138: 491-494, 1987.

6. Chamberlain $G$, and Needham P: The absorption of antibiotics from the bladder. J Urol 116: 172-173, 1976

7. Giannoni R, Legramandi $C$, and Fonte $A$ : Polyvinilpyrrolidone-iodine (P.V.P.-I) bladder irrigation for prevention of catheter-associated urinary infections in patients treated by T.U.R. Arch Ital Urol 61: 63-67, 1989.

8. Harper WES: An appraisal of 12 solutions used for bladder irrigation or instillation. $\mathrm{Br} J$ Urol 53: 433-438, 1981.

9. Harper WES, and Matz LR: Further studies on effects of irrigation solutions on rat bladders. Br J Urol 48: 463-467, 1976 
10. Harper WES, and Matz LR: The effect of chlorhexidine irrigation of the bladder of the rat. Br J Urol 47: 539-543, 1975.

11. Stickler DJ, Clayton CL, and Chawla JC: Assessment of antiseptic bladder washout procedures using a physical model of the catheterized bladder. Br J Urol 60: 413-418, 1987.

12. Salmela K, Eklund B, Kyllonen L, Isoniemi H, Korsback $C$, Hockerstedt $K$, and Ahonen J: The effect of intravesically applied antibiotic solution in the prophylaxis of infectious complications of renal transplantation. Transplant Int 3: 12-14, 1990.

13. Lapides J, Diokno AC, Silber SJ, Lowe BS: Clean, intermittent self-catheterization in the treatment of urinary tract disease. J Urol 107: 458-461, 1972.

14. Greenfield SP, and Fera M: The use of intravesical oxybutynin chloride in children with neurogenic bladder. J Urol (2 pt 2) 146: 532-534, 1991.

15. Massad CA, Kogan BA, and Trigo-Rocha FE: The pharmacokinetics of intravesical and oral oxybutynin chloride. J Urol (2 pt 2) 148: 595-597, 1992.

16. Kato K, Kitada S, Chun A, Wein AJ, and Levin RM: In vitro intravesical instillation of anticholinergic, antispasmodic and calcium blocking agents (rabbit whole bladder model). J Urol 141: 1471-1475, 1989.

17. University of Michigan Ambulatory Care Pharmacy: Prescription data, June 1992.

18. Cox CE: Gentamicin. Med Clin North Ann 54: 1305-1315, 1970.

19. Strausbaugh LJ, and Sande MA: Factors influencing the therapy of experimental Proteus mirabilis in rabbits. J Infect Dis 137: 251-260, 1978.

20. Chrai SS, and Ambrosio TJ: Gentamicin sulfate injec tion repackaged in syringes. Am J Hosp Pharm 34: 920, 1977.

21. Dinel BA, Ayotte DL, Behme RJ, Black BL, and Whitby JL: Comparative stability of antibiotic admixtures in minibags and minibottles. Drug Intell Clin Pharmacol 11: $226-239,1977$
22. Kowaluk EA, Roberts MS, Blackburn HD, and Polack $\mathrm{AE}$ : Interactions between drugs and polyvinyl chloride infusion bags. Am J Hosp Pharm 38: 1308-1314, 1981

\section{EDITORIAL COMMENT}

Intravesical instillation of antimicrobials provides a practical alternative to oral and parenteral therapy for bacteriuria in patients using intermittent catheterization. The study demonstrates that absorption of intravesical antibiotics is minimal when the agents are instilled under pressure in dogs without bacteriuria and in children using intermittent catheterization for neurogenic bladder. Serum gentamicin levels obtained thirty minutes after instillation showed no significant elevation. Repeated instillations and instillations in infected bladders under pressure however, might produce higher levels of the drug. If this approach were to be used continuously, monitoring of gentamicin levels would appear prudent.

In vitro activity of the drug was substantiated under a variety of conditions including storage at room temperature. In vitro susceptibility testing, however, does not always correlate with in vivo efficacy. It is possible that the drug's efficacy could be diminished in vivo after long-term storage.

The most important question to be addressed is the need for antibiotic irrigation at all. Bacilluria in this setting is rarely associated with a significant alteration in renal function. Although bacteriuria can lead to urinary tract infection and even sepsis, there is no evidence that this technique will prevent infectious sequelae over a long duration of time. It has been well established that chronic use of antibiotics can lead to resistant organisms. It could be argued that antibiotic therapy, even if administered intravesically, should be reserved for patients who have symptoms or signs of urinary tract infection.

Anthony J. Schaeffer, M.D.

Department of Urology (T229) Northwestern University 303 East Chicago Avenue

Chicago, Illinois 60611 